\title{
Calcium supplementation in pregnancy and prevention of hypertensive disorders in elderly women
}

\author{
Azar Aghamohammadi*, Mandana Zafari \\ Department of Midwifery, Sari Branch, Islamic Azad University, Sari, Iran \\ *Corresponding author, e-mail: azareaghamohamady@iausari.ac.ir
}

Received 21 Jun 2014

Accepted 26 Aug 2015

\begin{abstract}
Preeclampsia is a major cause of maternal and neonatal death and morbidity. Elderly women are at high risk for this complication. This study assesses the effect of calcium supplementation during pregnancy on preeclampsia in women aged over 35. Singleton healthy pregnant women over 35 with a normal blood pressure were randomly assigned to receive $1000 \mathrm{mg}$ /day of elemental calcium or placebo between the 18th and 20th weeks. From 89 women recruited in this study, 5 women in the calcium group and 4 women in the placebo group were excluded during the treatment as it was not possible to follow up their status. Finally, 80 women completed this study and were followed up until delivery. The incidence of preeclampsia was assessed in these 80 women ( 40 women in placebo and 40 women in the calcium group). The incidence of preeclampsia was significantly lower in the calcium group (15\%) than in the placebo group (35\%) $(p=0.035)$. Calcium supplementation appears to reduce the occurrence of preeclampsia and its related preterm birth in women singletons.
\end{abstract}

KEYWORDS: preeclampsia, pregnancy outcome

\section{INTRODUCTION}

Preeclampsia is a major cause of maternal and neonatal death and morbidity in the world. Preeclampsia is characterized by 3rd trimester supine blood pressure exceeding $140 \mathrm{mmHg}$ systolic and $90 \mathrm{mmHg}$ diastolic, or a rise of $30 \mathrm{mmHg}$ systolic or $15 \mathrm{mmHg}$ diastolic compared with the 1st trimester levels on two occasions at least $6 \mathrm{~h}$ apart, and proteinuria of $30 \mathrm{mg} / \mathrm{dl}$ measured by dipstick ${ }^{1}$. The incidence of preeclampsia is as high as $7-10 \%$ in the general population ${ }^{2}$. Unavoidable preterm birth in preeclampsia is one of the major causes of morbidity and mortality in these infants. Because of this, all strategies that will lead to significant reduction of preeclampsia and its significant impacts on maternal and prenatal outcome are important.

Despite many research efforts, the pathophysiology of preeclampsia remains uncertain. Such probable mechanisms consist of changes in vascular smooth muscle membrane stabilization and/or calcium-regulating hormones, natriuresis and associated changes in sodium homoeostasis, direct or indirect effects on cell $\mathrm{Ca}^{2+}$ metabolism, or depletion of phosphate ${ }^{3}$. The effect of calcium supplementation on the rate of preeclampsia was first introduced in $1980^{4}$. In recent years, there has been an increasing amount of literature on assessment of calcium intake and risk of preeclampsia.

Linares Segovia et al found that there is an association between preeclampsia and hypocalciuria ${ }^{5}$. Kazerooni et al in their study demonstrated that the existence of lower urine calcium to creatinine ratio in second trimester of pregnancy can predict hypertensive disorders in the third trimester ${ }^{6}$. Women with lower dietary milk intake showed an increasing rate of preeclampsia ${ }^{7}$. These results were confirmed by other studies ${ }^{7-10}$, and led to the hypothesis that an increase in calcium intake during pregnancy can prevent the high blood pressure and preeclampsia. High blood pressure in women with low calcium intake can stimulate parathyroid hormone, causing rennin release, or increasing intracellular calcium in vascular smooth muscle to induce vasoconstriction $^{11}$. It seems that calcium supplementation can reduce parathyroid hormone release and smooth muscle contractility. On the other hand it could also reduce uterine smooth muscle contractility and by this mechanism prevents preterm labour.

Jacobsson et al showed that severe preeclampsia was increased by raising the age ${ }^{12}$. The basic reason of increasing the preeclampsia measured in elderly women is unknown. Some studies suggested that the probability of aged women infection has a relationship with several pathogens that stimulate their immune system for rousing and increasing the 
probability of preeclampsia ${ }^{13}$. There is also a theory that, in aged women, preeclampsia distinction happens sooner than the young women ${ }^{14}$.

The aim of this study was to determine the effect of calcium supplementation during pregnancy in women over 35 years on the risk of preeclampsia, preterm birth and related maternal, foetal, and neonatal outcomes.

\section{MATERIALS AND METHODS}

After the study was approved by the research and Ethics Committee of Islamic Azad University, Sari Branch, 89 singleton healthy pregnant women who were outpatients of the obstetric clinic of Imam Khomeini Hospital in gestational age $\leqslant 18$ gave informed consent to participate in this study.

The participants were divided randomly (block randomization) into two groups of either calcium or placebo ( 44 women in the calcium group, and 45 women in the placebo group). From 89 women who entered in this study, 5 women in the calcium group and 4 women in the placebo group were excluded during treatment as their follow up was not possible. Finally, 80 women completed this study (40 women in placebo and 40 women in calcium group). In the calcium group, women received $1000 \mathrm{mg}$ /day of elemental calcium and in the placebo group they received the same shape and colour drug without any elemental calcium. Staff and participants were blinded to the drug contents.

All women received general prenatal care to term. Intervals between antenatal checkups were monthly before 28 weeks of gestation, every 2 weeks between 28 and 36 weeks, and then weekly until delivery. Blood pressure was measured (and controlled twice) from the right arm at each antenatal checkups, until delivery, and at $48 \mathrm{~h}$ after delivery. Gestational age was estimated by the last menstrual period, and ultrasonic measurement of foetal crown-rump length in early pregnancy.

Exclusion criteria in this study were age less than 35 years old, multiple pregnancies, hypertension or proteinuria in the first trimester, diabetes mellitus, renal disease, sickle cell anaemia, gestational age more than 18 weeks, smoking and addict persons, autoimmune disease and heart disease. 45 women received $1000 \mathrm{mg}$ of elemental calcium daily, beginning between the 18th and 20th weeks of gestation and continuing until delivery. 44 women in the control group received a placebo. Calcium supplementation intake was assessed at each visit. Women whose calcium supplementation was inadequate were excluded from the study. The criteria
Table 1 Characteristics of women in calcium and placebo groups (mean $\pm \mathrm{SD}$ ).

\begin{tabular}{lccc}
\hline & Calcium $(n=40)$ & Placebo $(n=40)$ & $p$-value \\
\hline Parity & $2.1 \pm 1.2$ & $2.5 \pm 1.4$ & 0.443 \\
BMI & $26.6 \pm 4.8$ & $27.0 \pm 3.9$ & 0.121 \\
Age & $36.9 \pm 1.9$ & $37.4 \pm 2.5$ & 0.06 \\
\hline
\end{tabular}

for a diagnosis of preeclampsia were 3rd trimester supine blood pressure exceeding $140 \mathrm{mmHg}$ systolic and $90 \mathrm{mmHg}$ diastolic, or a rise of $30 \mathrm{mmHg}$ systolic or $15 \mathrm{mmHg}$ diastolic compared with 1 st trimester levels on two occasions at least $6 \mathrm{~h}$ apart, and proteinuria of $30 \mathrm{mg} / \mathrm{dl}$ measured by dipstick ${ }^{3}$. Statistical analysis of the data was done with SPSS. A value of $p<0.05$ was considered significant.

This study was done after obtaining written permission from ethics committee of Islamic Azad university, sari Branch, Iran (Code: 92-45) in January of 2012 and this protocol is registered in Iranian registry of clinical trials (ID: IRCT201345635734N2).

\section{RESULTS}

There were no significant differences in the age, parity, or BMI between the groups (Table 1). During the study, 20 women developed preeclampsia. The incidence of preeclampsia in the 40 subjects managed on the calcium supplement was $6(15 \%)$, lower than that in the placebo group: $14(35 \%)$. The incidence of preterm birth, low birth weight, NICU admission in the placebo group was significantly higher than that in calcium group (Table 2). No participant in either group developed eclampsia.

\section{DISCUSSION}

The effect of calcium in reducing preeclampsia has been confirmed in several studies. In the present study, 89 singleton healthy pregnant women over 35 years with normal blood pressure were randomly assigned between the 18th and 20th weeks to receive $1000 \mathrm{mg} /$ day of elemental calcium and or placebo. From 89 women entered in this study 5 women in the calcium group and 4 women in the placebo group were excluded during treatment and their follow up was not possible and finally 80 women completed this study and were followed-up until delivery. Analysis was performed for these 80 women ( 40 women in placebo and 40 women in calcium group). The result of our study showed that the incidence of preeclampsia in the placebo group was $14(35 \%)$ and in calcium group was $6(15 \%)$, which were significantly different. 
Table 2 Incidence of pregnancy outcome in calcium and placebo groups.

\begin{tabular}{lccc}
\hline & Calcium $(n=40)$ & Placebo $(n=40)$ & $p$-value \\
\hline Preeclampsia & $6(15 \%)$ & $14(35 \%)$ & 0.035 \\
Preterm birth & $6(15 \%)$ & $9(22 \%)$ & 0.284 \\
Low birth weight & $8(20 \%)$ & $12(30 \%)$ & 0.22 \\
NICU admission & $3(8 \%)$ & $4(10 \%)$ & 0.5 \\
Apgar score in 5 min $<7$ & $2(5 \%)$ & $2(5 \%)$ & 0.692 \\
Systolic rise & $11.3 \pm 2.8$ & $12.1 \pm 3.4$ & 0.434 \\
Diastolic rise & $6.97 \pm 0.83$ & $7.92 \pm 0.27$ & 0.003 \\
\hline
\end{tabular}

In this regard, Purwar et al have reported that preeclampsia in a calcium group was $2 \%$ and in placebo group was $12 \%$ and this difference was significant ${ }^{15}$. But Levine et al have found no difference between calcium and placebo group in preeclampsia ${ }^{16}$. Belizán et al have demonstrated that the incidence of preeclampsia in the placebo group was $4 \%$ and in calcium group was $3 \%$, which did not differ significantly ${ }^{8}$. Many studies have confirmed the result of the present study for consuming calcium supplement to reduce preeclampsia and its complication. On the other hand, there are some studies that have not confirmed this benefit.

How calcium is effective in preeclampsia? It is believed that low calcium intake causes PTH and renin to increase and this causes an increase in intracellular calcium and leads to vasoconstriction and hypertension. Density of extracellular calcium does not increase by increasing calcium intake and this leads to reduction of nitric oxide (NO) secretion from the vascular endothelium. NO leads to vasoconstriction and hypertension. In the preeclampsia, NO was increased and calcium supplement may reduce preeclampsia by reducing NO. Recent evidence suggests that calcium could also increase magnesium levels and have an effect on smooth muscle function of the uteroplacental blood flow ${ }^{17}$.

Despite the results of some previous studies about a relation between calcium supplementation and gestational age and lower rates of preterm birth $^{18,19}$, our finding showed that there are no differences in pregnancy outcome such as preterm birth, low birth weight, NICU admission, and low Apgar scores between the two groups.

The present study showed that calcium supplementation can reduce the rate of preeclampsia in women beyond age 35 but recommendation of calcium supplementation in pregnancy for general population needs to be further investigated.

Acknowledgements: We thank Mr Jafari from Imam Khomeini hospital for helping us to do this study.

\section{REFERENCES}

1. Yamasmit W, Chaithongwongwatthana S, Charoenvidhya D, Uerpairojkit B, Tolosa J (2004) Random urinary protein-to-creatinine ratio for prediction of significant proteinuria in women with preeclampsia. J Matern Fetal Neonatal Med 16, 275-9.

2. Ray J, Vasishta K, Kaur S, Majumdar S, Sawhney H (1999) Calcium metabolism in pre-eclampsia. Int $J$ Gynecol Obstet 66, 245-50.

3. Ito M, Koyama H, Ohshige A, Maeda T, Yoshimura T, Okamura H (1994) Prevention of preeclampsia with calcium supplementation and vitamin D3 in an antenatal protocol. Int J Gynecol Obstet 47, 115-20.

4. Belizán J, Villar J (1980) The relationship between calcium intake and edema-, proteinuria-, and hypertension-gestosis: an hypothesis. Am J Clin Nutr 33, 2202-10.

5. Linares Segovia B, Tlatilpa Vega I, Cervantes Villarreal E, Amador Licona N (2004) Hypocalciuria during pregnancy as a risk factor of preeclampsia. Ginecol Obstet Méx 72, 570-4, [in Spanish].

6. Kazerooni T, Hamze-Nejadi S (2003) Calcium to creatinine ratio in a spot sample of urine for early prediction of pre-eclampsia. Int J Gynecol Obstet 80, 279-83.

7. Duvekot EJ, de Groot CJM, Bloemenkamp KWM, Oei SG (2002) Pregnant women with a low milk intake have an increased risk of developing preeclampsia. Eur J Obstet Gynecol Reprod Biol 105, 11-4.

8. Belizán J, Villar J, Repke J (1988) The relationship between calcium intake and pregnancy-induced hypertension: up-to-date evidence. Am J Obstet Gynecol 158, 898-902.

9. Villar J, Belizan JM, Fischer PJ (1983) Epidemiologic observations on the relationship between calcium intake and eclampsia. Int J Gynecol Obstet 21, 271-8.

10. Sirohiwal D, Dahiya K, Khaneja N (2009) Use of 24hour urinary protein and calcium for prediction of preeclampsia. Taiwan J Obstet Gynecol 48, 113-5.

11. Gasnier R, Valério EG, Vettorazzi J, Martins-Costa SH, Barros EG, Ramos JGL (2012) Calcium-to-creatinine ratio in pregnancy-induced hypertension. Pregnancy Hypertens 2, 59-64.

12. Jacobsson B, Ladfors L, Milsom I (2004) Advanced 
maternal age and adverse perinatal outcome. Obstet Gynecol 104, 727-33.

13. Studziński Z (2004) Pregnancy and delivery in women over 40 years old. Wiad Lek 57, 140-4, [in Polish].

14. Gilbert WM, Nesbitt TS, Danielsen B (1999) Childbearing beyond age 40: pregnancy outcome in 24032 cases. Obstet Gynecol 93, 9-14.

15. Purwar M, Kulkarni H, Motghare V, Dhole S (1996) Calcium supplementation and prevention of pregnancy induced hypertension. J Obstet Gynaecol Res 22, 425-30.

16. Levine RJ, Hauth JC, Curet LB, Sibai BM, Catalano PM, Morris CD, DerSimonian R, Esterlitz JR, et al (1997) Trial of calcium to prevent preeclampsia. New Engl J Med 337, 69-77.

17. Carroli G, Merialdi M, Wojdyla D, Abalos E, Campodonico L, Yao S-E, Gonzalez R, Deter R, et al (2010) Effects of calcium supplementation on uteroplacental and fetoplacental blood flow in lowcalcium-intake mothers: a randomized controlled trial. Am J Obstet Gynecol 202, 45.e1-9.

18. Cong K, Chi S, Liu G (1995) Calcium supplementation during pregnancy for reducing pregnancy induced hypertension. Chin Med J 108, 57-9.

19. Belizán JM, Villar J, Gonzalez L, Campodonico L, Bergel E (1991) Calcium supplementation to prevent hypertensive disorders of pregnancy. New Engl J Med 325, 1399-405. 